- Trabalho financiado pela We nnerGren Foundation for Anthropological Research, David C. Skomp Grant do Depar tamento de Antropologia (Indiana University) $e$ William and Flora Hewlett Foundation.

* Nucleo de Doenças Endêmicas Samuel Pessóa, Escola Nacional de Saúde Pública, Fio cruz.

\section{Parasitismo Intestinal Entre o Grupo Indígena Zoró, Estado de Mato Grosso (Brasil)*}

\author{
Carlos E. A. Coimbra Jr. ${ }^{* *}$ \\ Ricardo Ventura Santos**
}

Essa nota relata os resultados de inquérito parasitológico realizado entre o grupo indígena Zoró (Mato Grosso). Dentre os 173 exames realizados, foram encontradas $9(5,2 \%)$ amostras positivas para Ancilostomideos, 4 (2,3\%) para Trichuris trichiura, $5(2,9 \%)$ para Hymenolepis nana, $17(9,8 \%)$ para Giardia lamblia, $5(2,9 \%)$ para Balantidium coli $e$ $29(16,8 \%)$ para Entamoeba histolytica. Os autores observam a baixa prevalência de helmintoses e chamam a atenção para a possibilidade de controle dessas parasitoses em comunidades indígenas por meio de medicação em massa. Discutem, também, as implicaçóes epidemiológicas da prática de criar porcos selvagens no peridomicllio na transmissão do $\mathrm{B}$. coli.

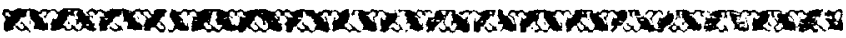

A prevalência de parasitas intestinais é reconhecidamente elevada entre populaçőes ameríndias, como pode ser constatada em recente revisão sobre o tema (cf. Salzano \& Callegari-Jacques, 1988). Em desacordo com esse quadro, os resultados por nós obtidos entre os Zoró chamam atenção pela baixa prevalência de helmintos e protozoários.

Do total de aproximadamente 220 indivíduos que constituíam a população Zoró em 1988, foram coletadas 173 (aproximadamente 79\%) amostras de fezes. Já que a população era reduzida, o objetivo foi uma amostragem universal da comunidade estudada. Os exames foram realizados pelo método de sedimentação de Lutz em amostras previamente fixadas em formol $10 \%$. Foram encontradas $9(5,2 \%)$ amostras positivas para Ancilostomf́deos, $4(2,3 \%)$ para Trichuris trichiura, $5(2,9 \%)$ para Hymenolepis nana, $17(9,8 \%)$ para Giardia lamblia, $5(2,9 \%)$ para Balantidium coli e $29(16,8 \%)$ para Entamoeba histolytica.

No que se refere aos helmintos, as baixas prevalências podem ser explicadas pelo fato da população vir sendo medicada em massa com mebendazol, administrado pelo Posto da Fundação Nacional do Índio (Funai) em intervalos de 4-5 meses. Esses resultados 
reforçam observaçōes feitas anteriormente, sugerindo que o tratamento em massa com anti-helmíntico de largo espectro pode ser eficaz no controle das geo-helmintoses em comunidades relativamente isoladas e fechadas como grupos indígenas (Santos et al. 1985a, b). $\mathrm{Na}$ oportunidade, chamou-se a atenção para o fato de que, tanto entre os grupos indígenas Karitiána (Santos et al. 1985a) como entre os Pakaanóva (Santos et al. 1985b), o anti-helmíntico vinha sendo administrado empírica e regularmente pelo atendente de saúde da Funai no Posto. Com o objetivo de maximizar o impacto dessa intervenção, são necessários estudos epidemiológicos, visando estabelecer qual seria o anti-helmíntico mais apropriado assim como os intervalos nos quais o mesmo deve ser ministrado.

$\hat{E}$ interessante chamar atenção para o achado de Balantidium coli em 2,9\% das amostras. Esse protozoário tem sido raramente reportado em inquéritos parasitológicos realizados entre populações indígenas da Amazônia (cf. Bruno, 1978 e Lawrence et al. 1980). Apenas em uma ocasião foi o $B$. coli observado associado a quadro grave de disenteria, tratando-se de uma mulher Yanomama (Rees \& Shelley, 1977). Entre os Zoró, os casos de parasitismo por $B$. coli eram assintomáticos.

Com relação a origem do $B$. coli entre sociedades indigenas, Lawrence et al. (1980) sugerem que, dado a sua raridade, o mesmo teria sido introduzido após o contato com sociedades de cultura ocidental, acompanhando a criação de animais domésticos reconhecidamente reservatórios do parasita, como o porco. Vale ressaltar, contudo, que o porco doméstico não é o único reservatório de $B$. coli. Porcos silvestres e diferentes espécies de primatas neotropicais já foram encontrados naturalmente infectados pelo protozoário (cf. Hoare, 1968; Wilcocks \& Manson-Bahr, 1972 e Martins \& Pessôa, 1977). Sendo assim, as fontes de infecção para o homem já se encontravam no Novo Mundo antes da chegada dos europeus e, portanto, casos de balantidíase entre sociedades indígenas da Amazônia podem ser explicados, pelo menos em parte, pela manipulação e ingestão de carcaça de mamíferos silvestres infectados.

Os Zoró não só caçam porcos selvagens (Brunelli, 1985), como também criam filhotes sempre que conseguem capturá-los na floresta. Os porquinhos são criados em pequenos "chiqueiros" adjacentes às habitaçōes até atingirem a idade adulta, quando então são soltos no pátio da aldeia e perseguidos até serem mortos por flechadas. Durante o evento festivo da matança do porco, o dono do animal recebe presentes dos que se lançam na perseguiçäo do animal, sendo estes constituídos principalmente por flechas. A proximidade de 
contato com porcos silvestres verificada entre os Zoró aliada à higiene precária são fatores epidemiológicos importantes no delineamento do quadro da balantidíase na comunidade. Vale salientar que o hábito de criar porcos selvagens no peridomicílio, como foi observado entre os Zoró, não é comum entre os grupos indígenas da regiāo amazônica. Os autores desconhecem referência a comportamento semelhante na literatura etnográfica.

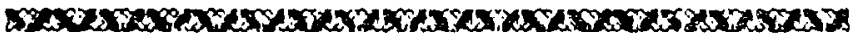

This paper reports on the results of a parasitological survey conducted among the Zoró Indians (Mato Grosso). From the total of 173 stool samples, 9 (5.2\%) were positive for Ancilostomidae, $4(2.3 \%)$ for Trichuris trichiura, $5(2.9 \%)$ for Hymenolepis nana, 17 (9.8\%) for Giardia lamblia, 5 (2.9\%) for Balantidium coli, and 29 (16.8\%) for Entamoeba hislolytica. The authors note the low prevalence of helminths and call attention for the possibilities of achieving control of these parasites among Amerindian communities by means of mass treatment. The authors also discuss the epidemiological implications of the practice of rearing wild pigs near the houses in the transmission of $\mathrm{B}$. coli.

\section{REFERÊNCIAS BIBLIOGRÁFICAS}

BRUNELLI, G. - Bebe! Bebe!... Jikkoi! Les Zorós vont à la chasse. Recherches Amerindiennes au Quebec, 15: 45-57, 1985.

BRUNO, A. A. G. - Condiçōes Sanitárias em Escolares em Zonas Rurais do Territbrio Federal do Amapa, Tese de Mestrado, Universidade Estadual de Campinas, Campinas, 1978.

HOARE, C. A. - The natural nidality of certain protozoan infections of man, In: Natural Nidality of Diseases and Questions of Parasitology (N. D. Levine \& F. K. Plous, organizadores), Urbana, Chicago e Londres, University of Chicago Press, 1968.

LA WRENCE, D. L.; NEEL, J. V.; ABADIE, S. H.; MOORE, L. L.; ADAMS, L. J.; HEALY, G. R. \& KAGAN, I. G. - Epidemiologic studies among Amerindian populations of Amazonia. III. Intestinal parasitoses in newly contacted and acculturating villages. Am. J. Trop. Med. Hyg., 29: 530-537, 1980 (Tradução para o portugués publicada em Acta Amazonica, 13 (2): 393-407, 1983).

MARTINS, A. V. \& PESSÔA, S. B. - Pessóa Parasitologia Médica, 10: Edição, Editora GuanabaraKoogan, Rio de Janeiro, 1977. 
REES, R. G. P. \& SHELLEY, A. J. - Estimativa quantitativa da resposta à clortetraciclina em um caso grave de disenteria por Balantidium coli. Acta Amazonica, 7: 47-49, 1977.

SALZANO, F. M. \& CALLEGARI-JACQUES, S. - South American Indians: A Case Study in Evolution, Clarendon Press, Oxford, 1988.

SANTOS, R. V.; COIMBRA JR., C. E. A. \& OTT, A. M., 1985 - Estudos epidemiológicos entre grupos indfgenas de Rondônia. III. Parasitoses intestinais nas populaçōes dos vales dos rios Guaporé e Mamore. Cadernos de Salide Pablica, 1: 467-477, 1985.

SANTOS, R. V;; TANUS, R. \& COIMBRA JR., C. E. A. - Prevalência de parasitoses intestinais no grupo indfgena Karitifna, Rondônia. Ciência e Cultura, 37 (Suplemento): 68, 1985.

WILCOCKS, C. \& MANSONBAHR, P. E. C. - Manson's Tropical Disease, 7: Edição, The William and Wilkind Co., Baltimore, 1972. 